legislation to extend the present system of voluntary controls on the safety of drugs in relation to their efficacy to a licensing system to control the marketing of all drugs. A licensing body under the Ministers for Health, for Agriculture and for Scotland will be responsible for issuing licences for clinical trials and for the release of new drugs and devices such as metal or plastic implants. Products already on the market will be automatically licensed, but their use will be gradually reviewed. Where the drug has a new principle, or there is some doubt as to its safety, efficacy or specification, it would be referred to one of the specialist committees. It seems likely that there will be a committee for the safety of drugs which may essentially be the present committee enlarged to include veterinary products, or may include two subcommittees for human and for veterinary products. Another committee would have to be responsible for the control of the quality of drugs and it would be this committee that would take over the direction of future editions of the British Pharmacopoeia from the General Medical Council. This may well be one of the first committees to begin its work and it is hoped that it will do so by February next year. Other committees, probably including one to advise on methods of inspection and on devices, will be formed in due course. The hope is that the whole system should become operational within about two years.

The commission will advise the ministers on the general pattern for these committees, and it can recommend people to serve on it. It will also hear appeals by applicants for licences against decisions by the expert committees.

It is hoped that by keeping the committees small, and not requiring them to examine every application in detail, the system will remain flexible. One question in doubt is the extent to which the commission will be responsible for classifying the relative efficacies of different drugs or for publishing the information for medical practitioners. There is an independent committee under Professor MacGregor which classifies drugs and issues a proprietary list and this may, in line with the recommendations of the Sainsbury report, come under the aegis of the committee. Another recommendation made in the Sainsbury report was that the commission should prepare information for doctors on new drugs before these are advertised. No provision is made for this in the new Act, but the commission will consider producing a journal such as the present Prescribers Journal in which information on drugs will be presented to practitioners.

\section{MEDICAL STATISTICS}

\section{New Clothes for Old Body}

The Medical Research Council's newly announced Statistical Research and Services Unit, housed in the University College Hospital Medical School in London, is remarkably similar to the Statistical Unit it was intended to replace. Only the size is different-the scientific staff now numbers three instead of nine. According to the director, Dr I. Sutherland, the unit will make explicit a function of advising other MRC establishments on statistical problems; previously this aid had always been given but was subordinated to the unit's own research.

The change of title came when Dr Richard Doll, who directed the Statistical Unit, took up the Regius Chair of Medicine at the University of Oxford at the beginning of July. With him went three of the unit's scientists and several of its research projects, mainly those dealing with cancer and the relation of thromboembolism to the contraceptive pill. Two more of the staff have transferred their affiliations to the MRC Clinical Research Centre, which should be opening at Harrow next year but at present consists of several divisions scattered around London.

Those who remain will still be pursuing a number of research lines on a budget of whose size Dr Sutherland says "nobody has the faintest idea". The work is to include the development and evaluation of statistical techniques for biological and medical data, and-for the moment-epidemiology, although this will eventually be dropped. New topics are expected later, when the staff rises to its projected size of five or six. There may also be cooperation with the MRC Computer Unit which was founded earlier this year, although the links so far are limited to borrowing computer facilities.

\section{SELECT COMMITTEES \\ New Enquiries}

THE eagle eye of the Select Committee on Science and Technology will this year be turned on the problems of population growth in the United Kingdom, while the Select Committee on Education and Science will tackle teacher training. The Select Committee on Science and Technology has also announced that it will be looking into an aspect of the computer industry and into atmospheric and river pollution, and it has appointed two sub-committees to resume the examination of the UK space research programme and to look at recent developments in carbon fibre technology. The committee, which was re-appointed only last week, has not yet decided on which aspects of these complex fields to concentrate, but its inquiries into the computer industry and the space research programme will probably involve examination of the prospects for European cooperation, and the carbon fibre inquiry is likely to be dominated by a recent decision of Imperial Chemical Industries not to produce the material.

The Select Committee on Education and Science began its inquiry into teacher training last session, and its decision to carry on is no surprise. It will be welcomed by the National Union of Teachers and by the National Union of Students, which have both campaigned for such an inquiry. The decision, however, follows hard on the heels of Mr Edward Short's statement that the Department of Education and Science is unlikely to institute an inquiry of its own.

The Select Committee on Science and Technology will have the following members: Mr David Ginsberg, Mr. Arnold Gregory, Mr Frank Hooley, Mr Robert L. Howarth, Mr Michae] Jopling, Mr Ted Ledbitter, Sir Harry Legge-Bourke, Mr Eric Lubbock, Mr Patrick MoNair-Wilson, Mr Eric Moonman, Mr Airey Neave, Mr Arthur Palmer (chairman), Mr Brian Parkyn and Mr David Price. Members of the Select Committee on Education and Science are: Mr Walter Aldritt, $\mathrm{Mr}$ Ronald Bell, Mr Donald Dewar, Mr Richard Hornby, Mr Gilbert Longden, Mr Kenneth Marks, Mr Richard Mitchell, Mr Trevor Park, Mr Christopher Price, Mr Arnold Shaw, Mr van Straubenzee, Mr Frederick Willey (chairman) and Mr Esmond Wright. 